\title{
Analysis of glycosaminoglycans in rabbit cornea after excimer laser keratectomy
}

\begin{abstract}
Takuji Kato, Kiyoo Nakayasu, Kazuyuki Ikegami, Takeo Obara, Toshiji Kanayama, Atsushi Kanai
\end{abstract}

\begin{abstract}
Backgroundlaims-The biochemical basis for the development of subepithelial opacity of the cornea after excimer laser keratectomy has yet to be fully defined. The aim of this study was to evaluate the alterations of glycosaminoglycans (GAGs) after excimer laser keratectomy.

Methods-Rabbit corneas were harvested on days 5, 10, 20, and 30 after excimer laser photoablation. The amount of main disaccharide units was determined by high performance liquid chromatography (HPLC). In addition, immunohistochemical studies were performed on corneal sections 20 days after the ablation.

Results-The concentrations of $\Delta \mathrm{Di}-0 \mathrm{~S}$ at 5 and 10 days were significantly lower than before the ablation. $\triangle D i-6 S$ showed a significant increase 5 days after the ablation but $\Delta \mathrm{Di}-4 \mathrm{~S}$ did not show any significant change. There was a significant increase in $\triangle \mathrm{Di}-\mathrm{HA}$ at 20 and 30 days after ablation. In immunohistochemistry, the positive staining for $\Delta \mathrm{Di}-6 \mathrm{~S}$ and hyaluronic acid was observed in the subepithelial region. These immunohistochemical results were well correlated with the HPLC findings.

Conclusions-The increase in chondroitin-6 sulphate and hyaluronic acid may be related to corneal subepithelial opacity after excimer laser keratectomy. (Br f Ophthalmol 1999;83:609-612)
\end{abstract}

In recent years, excimer laser photorefractive keratectomy (PRK) has been used widely to reduce myopia. ${ }^{1-5}$ The postoperative results of this procedure are fairly good although some undesirable adverse effects have been reported. ${ }^{6}$ Because PRK is performed on the central zone of the cornea, postoperative corneal haze is one of the most important clinical complications.

Although many studies have been performed to try to determine the basis for the corneal haze ${ }^{8-13}$ little is known about the biochemical changes during the development of the corneal haze. Glycosaminoglycans (GAGs) may play a major role in keeping the distance between collagen fibrils and contribute to the corneal transparency. ${ }^{14-17}$ Previous studies ${ }^{810} 13$ have provided data indicating that GAGs may be involved in the development of subepithelial opacity after PRK. For a better understanding of this phenomenon, we investigated the changes in GAG disaccharides quantitatively after excimer laser photoablation.
Materials and methods

SURGICAL PROCEDURES

All experimental procedures conformed to the ARVO statement for the use of animals in ophthalmic and vision research. Excimer laser photoablation was performed on 18 white rabbits using an EC-5000 excimer laser system (Nidek, Japan). All procedures employed a 193 $\mathrm{nm}$ emission wavelength, a $5 \mathrm{~mm}$ diameter ablation zone, $120 \mathrm{~mJ} /$ pulse, and a $30 \mathrm{~Hz}$ pulse repetition rate. The laser was calibrated before every procedure, and the depth of the ablation was $100 \mu \mathrm{m}$. Postoperative treatment included tobramycin drops four times daily for the first week.

HPLC

Corneal buttons of $6 \mathrm{~mm}$ were punched out on days 5, 10, 20, and 30 after ablation and immediately stored in cold acetone at $-20^{\circ} \mathrm{C}$. After drying in a vacuum desiccator and weighing, the sample corneas were treated in $100 \mu \mathrm{l}$ of $0.5 \mathrm{M} \mathrm{NaOH}$ overnight at $4^{\circ} \mathrm{C}$, neutralised with $100 \mu \mathrm{l}$ of $0.5 \mathrm{M} \mathrm{HCl}$, and digested with $200 \mu \mathrm{l}$ of $0.05 \mathrm{M}$ TRIS-acetate buffer ( $\mathrm{pH} 8.0$ ) containing $1 \%$ actinase $\mathrm{E}$ at $50^{\circ} \mathrm{C}$ for 24 hours. To the digested solution, $3.6 \mathrm{ml}$ of cold ethanol saturated with sodium acetate was added and GAGs were precipitated by keeping the solution overnight at $4^{\circ} \mathrm{C}$. Crude GAGs were collected by centrifugation at $1800 \times g$ for 15 minutes, dried in a vacuum desiccator, and then dissolved in $500 \mu 1$ of distilled water. Each $100 \mu \mathrm{l}$ portion was digested with chondroitinase $\mathrm{ABC}$ and $\mathrm{AC}-\mathrm{II}$ or chondroitinase AC-II.

A $100 \mu \mathrm{l}$ portion of crude GAGs solution and $100 \mu \mathrm{l}$ of $0.1 \mathrm{M}$ TRIS-HCl buffer $(\mathrm{pH}$ 8.0) containing both chondroitinase $\mathrm{ABC}$ and chondroitinase AC-II (0.2 U each, Seikagaku Kogyo, Tokyo, Japan) were mixed and incubated at $37^{\circ} \mathrm{C}$ for 3 hours. To another $100 \mu \mathrm{l}$ portion of crude GAGs solution were added $100 \mu 1$ of $0.1 \mathrm{M}$ acetate buffer ( $\mathrm{pH}$ 6.0) containing chondroitinase AC-II $(0.2 \mathrm{U})$, then the mixture was incubated at $37^{\circ} \mathrm{C}$ for 3 hours. A $20 \mu \mathrm{l}$ volume of the reaction mixture was subjected to HPLC. ${ }^{18}$ The HPLC conditions were as follows: a TSK-gel $\mathrm{NH}_{2}-60$ column $(250 \mathrm{~mm} \times 4.6 \mathrm{~mm} \mathrm{ID}$, Tosoh, Tokyo, Japan) was eluted at $30^{\circ} \mathrm{C}$ with acetonitrile$0.1 \mathrm{M}$ TRIS-HCl buffer ( $\mathrm{pH} 7.5$ ) containing $0.15 \mathrm{M}$ boric acid and $6.5 \mathrm{mM}$ sodium sulphate $(3: 2, \mathrm{v} / \mathrm{v})$ at flow rate $0.5 \mathrm{ml} / \mathrm{min}$. To the elute were added $0.3 \mathrm{M}$ sodium hydroxide and aqueous 1\% 2-cyanoacetamide solution containing $1 \mathrm{mM}$ ethylenediaminetetracetic acid at the same flow rate of $0.25 \mathrm{ml} / \mathrm{min}$. The mixture passed through a dry reaction bath thermostatically controlled at $110^{\circ} \mathrm{C}$ and
Accepted for publication 2 December 1998 
A

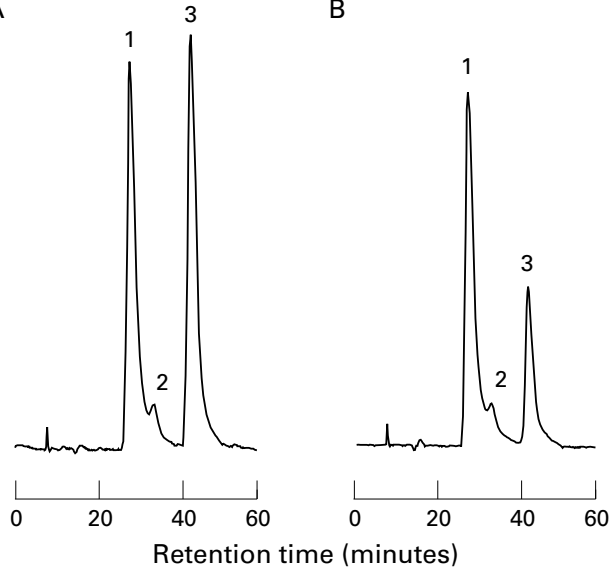

Figure 1 Chromatograms of unsaturated disaccharides produced from rabbit corneal glycosaminoglycans by digestion with enzymes. (A) Digested with chondroitinase $A B C$ together with chondroitinase $A C-I I ;(B)$ digested with chondroitinase AC-II. Peaks: $1=\Delta D i-0 S ; 2=\Delta D i-6 S ; 3$ $=\triangle D i-4 S . \triangle D i-H A$ was not determined in normal rabbit corneal glycosaminoglycans.

monitored fluorimetrically (excitation 346 $\mathrm{nm}$, emission $410 \mathrm{~nm}$ ). The GAGs are converted by enzymatic digestion into oligosaccharides which contain one terminal $\Delta^{4}$ 5-unsaturated glucopyranosyluronic acid. ${ }^{18}$ Chondroitinase ABC digests chondroitin (Ch), chondroitin 4-sulphate (C-4S), chondroitin 6-sulphate (C-6S), dermatan sulphate (DS), and hyaluronic acid (HA) to the corresponding unsaturated disaccharides $(\Delta \mathrm{Di}-0 \mathrm{~S}, \Delta \mathrm{Di}-4 \mathrm{~S}, \Delta \mathrm{Di}-6 \mathrm{~S}, \Delta \mathrm{Di}-4 \mathrm{~S}, \Delta \mathrm{Di}-\mathrm{HA})$. Chondroitinase AC-II functions on $\mathrm{Ch}, \mathrm{C}-4 \mathrm{~S}$, C-6S, and HA, but not on DS. Based on the differences in enzymatic digestion of GAGs, reliable determinations of $\mathrm{Ch}, \mathrm{C}-6 \mathrm{~S}, \mathrm{C}-4 \mathrm{~S}$, DS, and HA were performed. Furthermore, disaccharide production was perfected with the combined digestion with chondroitinase ABC and AC-II. ${ }^{18}$ Commercial unsaturated disaccharides (Seikagaku Kogyo) were used as standard. Statistical analysis was performed by Tukey-Kramer multiple analysis.

IMMUNOHISTOCHEMISTRY

Rabbit corneas obtained on day 20 after photoablation were frozen in Tissue Tek II OCT compound (Baxter Scientific, Columbia, MD, USA). Cryostat sections of $7 \mu \mathrm{m}$ were placed on silane coated slides and air dried at room temperature for 2 hours and then fixed in acetone. Sections were preincubated with $3 \%$ hydrogen peroxide in phosphate buffered saline (PBS) followed by treatment with chondroitinase ABC. Digestion was performed at $37^{\circ} \mathrm{C}$ for 1 hour with $0.2 \mathrm{U} / \mathrm{ml}$ of the enzyme in $20 \mathrm{mM}$ TRIS-HCl buffer $\mathrm{pH} 8.0$ as described previously. ${ }^{19}$

After treatment with $1 \%$ bovine serum albumin to block non-specific binding of antibodies, the sections were incubated for 1 hour at room temperature with mouse monoclonal antibodies specific for $\Delta \mathrm{Di}-4 \mathrm{~S}(2-\mathrm{B}-6)$, or for $\triangle \mathrm{Di}-6 \mathrm{~S}(3-\mathrm{B}-3)$ (Seikagaku Kogyo). After washing with PBS, the sections were incubated for 30 minutes with biotinylated anti-mouse IgG antibody (Dako, Carpinteria, CA, USA) in PBS, rinsed in PBS for 5 minutes, and then incubated with streptavidin-horseradish peroxidase (Dako), diluted in PBS, for 20 minutes. After extensive washing with PBS, bound antibodies were visualised by the diaminobenzidine reaction. Control experiments were performed using preimmune IgG or PBS in place of the primary antibodies. The distribution of hyaluronic acid was detected by using biotinylated hyaluronic acid binding

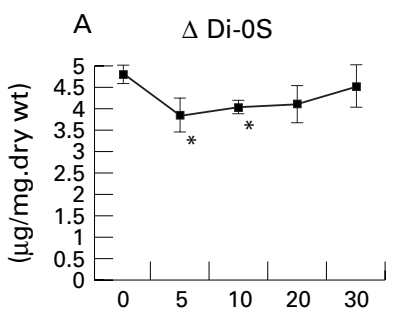

Postoperative time (days)

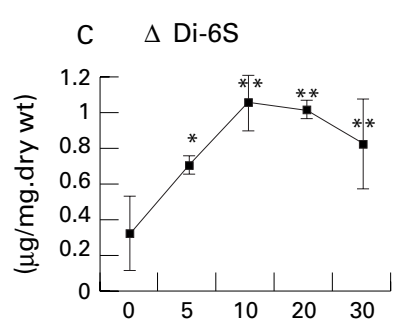

Postoperative time (days)

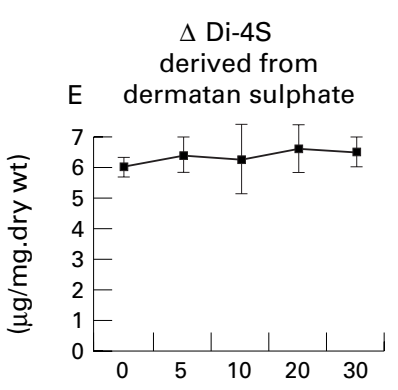

Postoperative time (days)
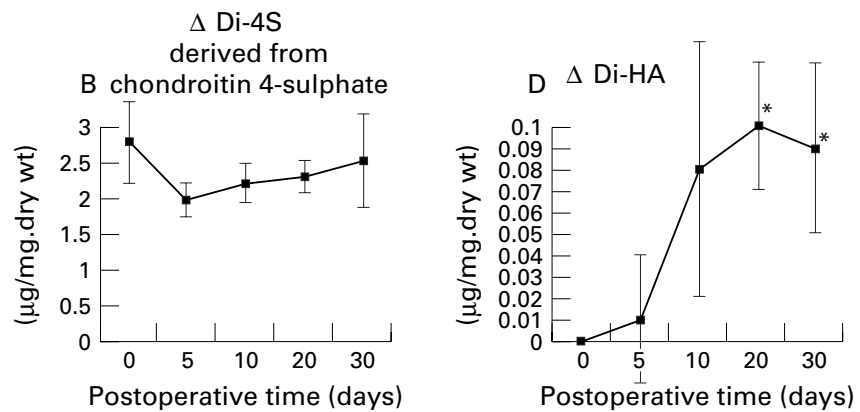

Figure 2 Postoperative change of $\triangle D i-0 S(A), \triangle D i$-4S derived from chondroitin 4-sulphate (B), $\triangle D i-6 S(C), \triangle D i-H A$ (D), and $\triangle D i-4 S$ derived from dermatan sulphate (E). Data represent mean (SD) for four experiments, ${ }^{*} p<0.05$; ${ }_{*} p<0.01$; significantly different from preoperative values by Tukey's multiple analysis. 

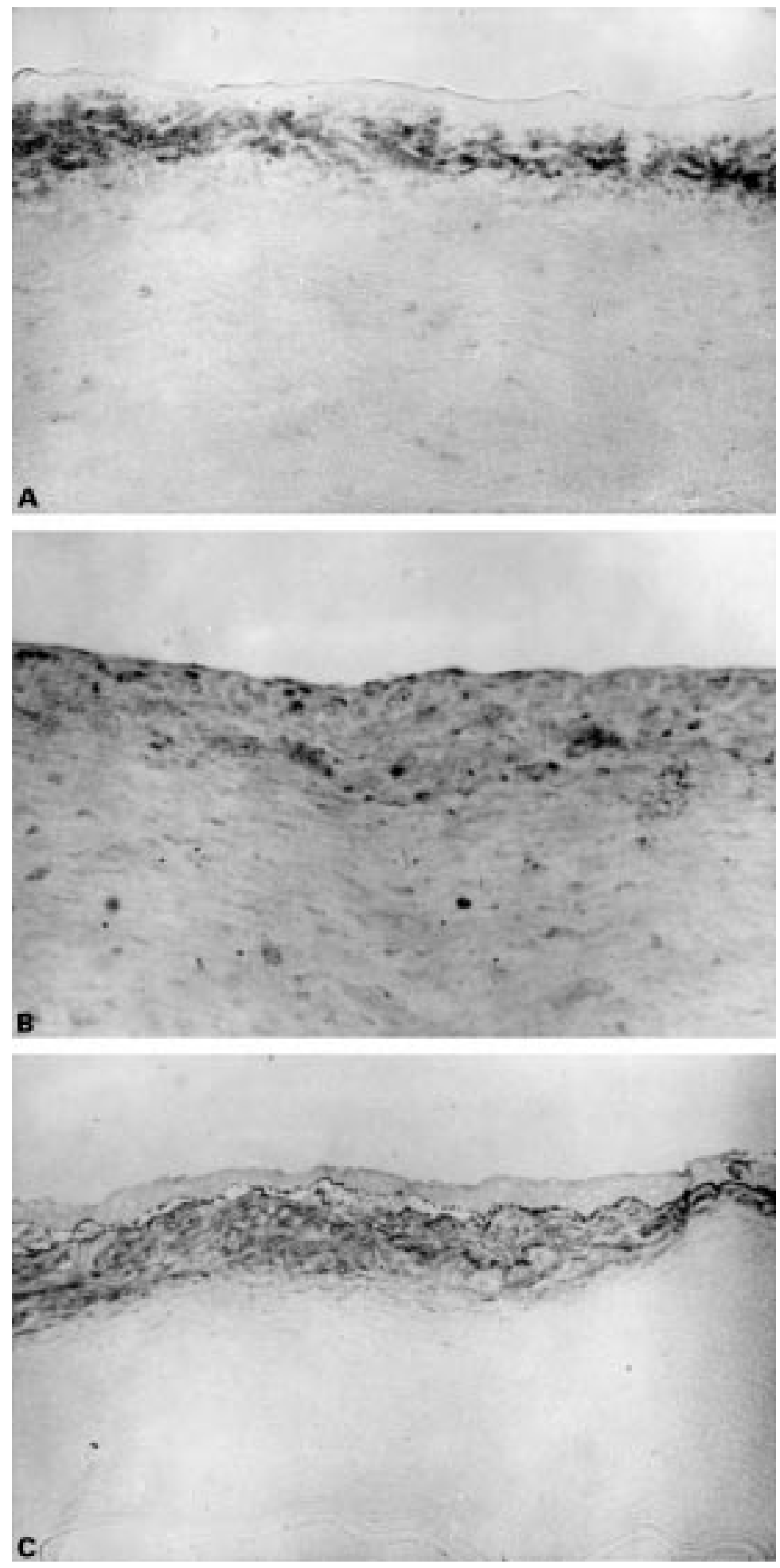

Figure 3 Immunohistochemical staining of $\Delta D i-6 S(A), \Delta D i-4 S(B)$, and hyaluronic acid $(C)$ in the anterior side of rabbit cornea, obtained at 20 days after PRK. Note that intensive staining for $\triangle D i-6 S(A)$ and hyaluronic acid $(C)$ are observed in the subepithelial region. Original magnification $\times 100$.

protein (B-HABP) (Seikagaku Kogyo). The sections were incubated for 1 hour at room temperature with B-HABP $(2 \mathrm{~g} / \mathrm{ml})$, and then $\mathrm{B}-\mathrm{HABP}$ was visualised with the same methods as described above. For the HA staining, control sections were pretreated with 200 $\mathrm{TRU} / \mathrm{ml}$ of hyaluronidase (Seikagaku Kogyo) for 1 hour at $60^{\circ} \mathrm{C}$ as described previously. ${ }^{20}$ In addition, negative controls in which the $\mathrm{B}-\mathrm{HABP}$ were omitted was stained at the same time.

\section{Results}

Figure 1 shows typical chromatograms of unsaturated disaccharides produced from rabbit corneal GAGs by combined digestion with chondroitinase ABC and AC-II (Fig 1A), and by chondroitinase AC-II (Fig 1B). The differences in the peak heights of $\triangle \mathrm{Di}-4 \mathrm{~S}$ in the two chromatograms (Fig $1 \mathrm{~A}$ and $\mathrm{B}$ ) correspond to the amounts of dermatan sulphate.

Figure 2 summarises the results obtained for the amounts of disaccharide units in rabbit corneas.

$\triangle \mathrm{Di}-0 \mathrm{~S} \quad(2$-acetamido-2-deoxy-3-O- $(\beta-\mathrm{D}-$ gluco-4-enepyranosyluronic acid)-D-galactose) as determined by HPLC was significantly decreased at 5 and 10 days after photoablation but the level gradually recovered with time. $\triangle \mathrm{Di}-0 \mathrm{~S}$ level at 20 and 30 days was not significantly different from the control values (Fig $2 \mathrm{~A})$. The $\Delta \mathrm{Di}-4 \mathrm{~S}$ (2-acetamido-2-deoxy-3-O( $\beta$-D-gluco-4-enepyranosyluronic acid)-4-Osulpho-D-galactose) (derived from chondroitin 4 -sulphate) level was slightly decreased 5 days after photoablation but the decrease was not significantly different from that of the control. The $\Delta \mathrm{Di}-4 \mathrm{~S}$ level gradually recovered with time (Fig 2B).

In contrast, photoablation resulted in a 3.3-fold increase $(p=0.00013)$ in the $\Delta \mathrm{Di}-6 \mathrm{~S}$ (2-acetamido-2-deoxy-3-O-( $\beta$-D-gluco-4-enepyranosyluronic acid)-6-O-sulpho-D-galactose) level at 10 days, and this higher level was maintained for up to 30 days after treatment (Fig $2 \mathrm{C}$ ). The $\triangle \mathrm{Di}$-HA (2-acetamido-2-deoxy-3-O( $\beta$-D-gluco-4-enepyranosyluronic acid)-D-glucose) level gradually increased with time, and at 20 days, the increase was significantly different from the control value $(p=0.018$; Fig 2D). There were no statistically significant changes in the $\Delta \mathrm{Di}-4 \mathrm{~S}$ (derived from dermatan sulphate) level after PRK treatment during the 30 day assay period (Fig 2E).

Immunohistochemistry on day 20 showed heavy staining for $\Delta \mathrm{Di}-6 \mathrm{~S}$ which was broadly distributed across the anterior stroma but the staining was limited to the ablated region (Fig 3A). In contrast, no increased staining for $\Delta \mathrm{Di}-4 \mathrm{~S}$ was observed (Fig $3 \mathrm{~B}$ ). The immunostaining for hyaluronic acid showed a similar increase to that observed for $\Delta \mathrm{Di}-6 \mathrm{~S}$. (Fig 3C). No staining was observed in negative control sections.

\section{Discussion}

The regression of the myopic correction and subepithelial haze have been reported as problems associated with excimer laser surgery. ${ }^{6}{ }^{7}$ Since the advent of laser ablation, the manifestation of a subepithelial haze accompanying the healing of wounds has become a major problem clinically. The composition of the corneal haze has been examined by histochemical and immunohistochemical methods. ${ }^{911-13}$ With reference to GAG levels during the healing of corneal wounds after excimer laser ablation, Fitzsimmons et $\mathrm{al}^{8}$ reported an increase in HA 
consistent with the corneal subepithelial haze after excimer laser ablation in rabbits, while Malley et $a l^{9}$ reported a decrease of keratan sulphate and Rawe et $a l^{10}$ found proteoglycans larger than normally in the cornea by electron microscopy. However, the study that analysed changes of glycosaminoglycan disaccharides in the cornea quantitatively over time following excimer laser have been reported here for the first time.

In the present study, we analysed the changes in GAG disaccharides in rabbit corneas quantitatively after excimer laser ablation using HPLC. Of the different methods to quantify GAGs, analysis of enzyme decomposition products by HPLC as used in the present study is an excellent method that will provide the types and quantity of the GAGs with only small quantities of samples. Although keratan sulphate (KS) is a major GAG in rabbit cornea, both chondroitinase $\mathrm{ABC}$ and AC-II do not act on KS, so the measurement of $\mathrm{KS}$ is not possible by this methods.

Our observation of an increase in HA following excimer ablation agrees with the report by Fitzsimmons et $\mathrm{al}^{8}$ in spite of the fact that different methods were used in the two studies. We found a decrease in $\triangle \mathrm{Di}-0 \mathrm{~S}$ immediately after surgery and an increase in $\triangle \mathrm{Di}-6 \mathrm{~S}$ and $\triangle \mathrm{Di}-\mathrm{HA}$ thereafter. On immunohistochemical examination, the increase in $\triangle \mathrm{Di}-6 \mathrm{~S}$ and hyaluronic acid was well correlated with the site of the subepithelial haze.

The increase in $\triangle \mathrm{Di}-6 \mathrm{~S}$ and hyaluronic acid was found 10-30 days after surgery which coincides with the time for the subepithelial haze to develop clinically. Since $\Delta \mathrm{Di}-6 \mathrm{~S}$ is the main unit of chondroitin 6-sulphate and hyaluronic acid is composed of $\triangle \mathrm{Di}-\mathrm{HA}$, our HPLC data may reflect the increase in chondroitin 6-sulphate and hyaluronic acid in the subepithelial region. Thus, the correlation of the locus and time of the increase in chondroitin 6-sulphate and hyaluronic acid with the subepithelial haze strongly suggest a probable causal relation.

Of the glycosaminoglycan disaccharides, $\Delta \mathrm{Di}-4 \mathrm{~S}$ did not show any significant change after surgery, while $\Delta \mathrm{Di}-6 \mathrm{~S}$ increased about 3.3 times, which is of great interest. Hasty et $a l^{21}$ have reported that hyaluronic acid and chondroitin 6-sulphate increase in the healing process of rabbit auditory cartilage wounds. Furthermore, Oya et $a l^{22}$ have reported that $\Delta \mathrm{Di}-6 \mathrm{~S}$ in the tears increases during the healing of corneal epithelial wounds in rabbits. Presumably, the increase of chondroitin 6 -sulphate at the wound site is a ubiquitously phenomenon as a general healing reaction of wounds.

It is of interest to note that in a histological comparison of corneas subjected to ablation by excimer laser with those that received a mechanical anterior keratectomy, both procedures induced subepithelial haze and the haze did not differ histochemically or immunohistochemically. ${ }^{913}$ Thus, it was concluded that the postoperative subepithelial haze is not a specific reaction to excimer laser but a general reaction during wound healing.
In summary, the increase in $\triangle \mathrm{Di}-6 \mathrm{~S}$ and $\triangle \mathrm{Di}-\mathrm{HA}$ as found in the HPLC study corresponds well with the results of immunohistochemical examination. Taken together with previous observations, our findings of an increase of $\Delta \mathrm{Di}-6 \mathrm{~S}$ and $\Delta \mathrm{Di}-\mathrm{HA}$ by quantitative HPLC and by immunohistochemical examination suggest that chondroitin 6-sulphate and hyaluronic acid play an important role in the subepithelial haze after excimer laser ablation.

Interspecies difference may exist in wound healing response and the composition of corneal GAGs varies from rabbit to human, ${ }^{14}$ so we must use caution when extrapolating these data to human cases.

1 Sher NA, Hardten DR, Fundingsland B, et al. 193-nm excimer photorefractive keratectomy in high myopia. Ophthalmology 1994;101:1575-82.

2 Dutt S, Steinert RF, Raizman MB, et al. One-year results of excimer laser photorefractive keratectomy for low to moderate myopia. Arch Ophthalmol 1994;112:1427-36.

3 Maguen E, Salz JJ, Nesburn AB, et al. Results of excimer laser photorefractive keratectomy for the correction of myopia. Ophthalmology 1994;101:1548-56.

4 Epstein D, Fagerholm P, Hamberg-Nystrom $\mathrm{H}$, et al. Twenty-four-month follow-up of excimer laser photoreTwenty-four-month follow-up of excimer laser photore-
fractive keratectomy for myopia. Refractive and visual acuity results. Ophthalmology 1994;101:1558-63.

5 Hersh PS, Stulting RD, Steinert RF, et al. Results of phase III excimer laser photorefractive keratectomy for myopia. The Summit PRK Study Group. Ophthalmology 1997;104: 1535-53.

6 Seiler T, Holschbach A, Derse M, et al. Complications of myopic photorefractive keratectomy with the excimer laser. Ophthalmology 1994;101:153-60.

7 Loewenstein A, Lipshitz I, Varssano D, et al. Complications of excimer laser photorefractive keratectomy for myopia. $\mathcal{f}$ Cataract Refract Surg 1997;23:1174-6.

8 Fitzsimmons TD, Fagerholm P, Harfstrand A, et al. Fitzsimmons TD, Fagerholm P, Harfstrand A, et al.
Hyaluronic acid in the rabbit cornea after excimer laser superficial keratectomy. Invest Ophthalmol Vis Sci 1992;33: 3011-6.

9 Malley DS, Steinert RF, Puliafito CA, et al. Immunofluorescence study of corneal wound healing after excimer laser anterior keratectomy in the monkey eye. Arch Ophthalmol 1990;108:1316-22.

10 Rawe IM, Zabel RW, Tuft SJ, et al. A morphological study of rabbit corneas after laser keratectomy. Eye 1992;6:637-42.

11 Hanna KD, Pouliquen Y, Waring GO III, et al. Corneal stromal wound healing in rabbits after 193-nm excimer laser surface ablation. Arch Ophthalmol 1989;107:895-901.

12 Anderson JA, Binder PS, Rock ME, et al. Human excimer laser keratectomy. Immunohistochemical analysis of healing. Arch Ophthalmol 1996;114:54-60.

13 Nakayasu K Goto T, Ishikawa T, et al. Glycosaminoglycans in subepithelial opacity after excimer laser keratectomy. in subepithelial opacity after excimer laser kera

14 Scott JE, Bosworth TR. A comparative biochemical and ultrastructural study of proteoglycan-collagen interaction in corneal stroma. Biochem f 1990;270:491-7.

15 Scott JE, Cummings C, Greiling H, et al. Examination of corneal proteoglycans and glycosaminoglycans by rotary hadowing and electron microscopy. Int $\mathcal{F}$ Biol Macromol 1990;12:180-4.

16 Scott JE. Proteoglycan: collagen interactions and corneal ultrastructure. Biochem Soc Trans 1991;19:877-81.

17 Scott JE. Morphometry of cupromeronic blue-stained proteoglycan molecules in animal corneas, versus that of purified proteoglycans stained in vitro, implies that tertiary structures contribute to corneal ultrastructure. F Anat 1992;180:155-64.

18 Toyoda H, Motoki K, Tanikawa M, et al. Determination of human urinary hyaluronic acid, chodroitin sulphate and dermatan sulphate as their unsaturated disaccharides by high-performance liquid chromatography. $\mathcal{f}$ Chromatogr high-performance

19 Fukatsu T, Sobue M, Nagasaka T, et al. Immunohisto chemical localization of chondroitin sulfate and dermatan sulphate proteoglycans in tumor tissues. Br f Cancer 1988; 57:74-8.

20 Asari A, Miyauchi S, Miyazaki K, et al. Intra- and extracellular localization of hyaluronic acid and proteoglycan constituents (chondroitin sulfate, keratan sulfate, and protein core) in articular cartilage of rabbit tibia. F Histochem Cytochem 1992;40:1693-704.

21 Hasty KA, Smith G Jr, Kang AH. Studies on glycosaminoglycans of regenerating rabbit ear cartilage. Dev Biol 1981;86:198-205.

22 Oya T, Obata $\mathrm{H}$, Miyata $\mathrm{K}$, et al. Quantitative analysis of glycosaminoglycans in tear fluids during corneal epithelial wound healing in rabbits. Nippon Ganka Gakkai Zasshi 1994;98:1049-55. 